\title{
ABISMOS E INOVAÇÕES NA POETICA MULTIFORME DE VICTOR HUGO
}

\author{
LORETO, Mari Lúcie da Silva ${ }^{1}$
}

Resumo: O presente estudo busca trazer à discussão o trânsito entre o verbal e visual na produção de Victor Hugo, comumente apenas conhecido como escritor. Sua produção artística além de vasta, com mais de quatro mil obras jamais expostas durante sua vida, está impregnada de originalidade e muitos elementos vanguardistas. A poética de Victor Hugo é multiforme, no ritmo de seus textos, desenhos ou pinturas. A pesquisa investiga traços de inovação nos processos gráficos e sua influência nas vanguardas artísticas no inicio do século XX.

Palavras-chave: Victor Hugo, estética, artes visuais, processos inovadores.

\section{INTRODUÇÃO}

O interesse de investigar os traços inovadores na poética de Victor Hugo surgiu ao me deparar com as os desenhos e pinturas do artista em duas exposições realizadas em 2000, no Museu Thyssen Bornemisza em Madrid e em 2002, na Biblioteca Nacional da França em Paris. A experiência de visualizar estas obras com traços e técnicas inovadoras para o momento de sua produção suscitou o interesse de conhecer um pouco mais sua poética.

Victor Hugo normalmente é apenas conhecido como escritor, sua produção artística praticamente desconhecida durante sua vida, apresenta originalidade e traços vanguardistas. Baudelaire reconhece a importância de sua obra visual, ao considerar Victor Hugo como o único pintor à altura de Delacroix. Baudelaire observa, ainda, que

\footnotetext{
${ }^{1}$ Doutora em Literatura Comparada UFRGS, Centro de Artes/UFPel, mari_lucie@yahoo.com
} 
a técnica de Victor Hugo é liberada de qualquer timidez, é um processo de pesquisa não dogmático. A originalidade está sempre presente nos processos gráficos que o artista emprega quando usa diferentes materiais de modo não convencional.

Victor Hugo viveu no século XIX, seguidamente considerado como um Homem Oceano, profundo, político, ativo e intenso. Victor Hugo l'homme océan foi o nome dado à mostra de 2002, realizada em Paris, na França. Com inúmeras qualidades ele enfrentou muitos momentos históricos diferentes e passou por eles de modo atuante. Morettto (2003) recorda que Victor Hugo presenciou o Primeiro Império de Napoleão I, a Restauração, a Revolução de 1830, a Monarquia de Julho de Luis Felipe de Orléans, a Revolução de 1848, o Segundo Império de Napoleão III e a Terceira República, a partir de 1870.

Nasceu em 1802 e faleceu em 1885, parou de escrever aos 81 anos, ou seja, dois anos antes de sua morte. Assim, o escritor preenche todo o século XIX, precursor do Romantismo, encaminhando a literatura francesa para a Modernidade. (MORRETO, 2003, p.9)

Engajado em palavras e atos, Victor Hugo possui intensa atividade social e política, membro do Comitê das Artes e Monumentos, indicado pela Academia Francesa de Letras (1841), eleito deputado da Constituinte (1848), e para a Assembleia Legislativa (1849) luta contra causas sociais como a pena de morte, a miséria, e a liberdade do ensino. Em seu processo de criação encontramos marcas da atividade política.

Nos meandros culturais, Victor Hugo perpassa muitos movimentos como o Neoclassicismo, o Romantismo, o Realismo, o Naturalismo e quase se depara com a publicação das primeiras obras de Rimbaud, e as inovações simbolistas que ascendem a Modernidade.

É este o panorama da época em que viveu Victor Hugo, nesse século agitado que desenvolveu a civilização industrial, em que a pequena mas também a grande burguesia foram se instalando nas cidades, que começavam a crescer, e em que a Ciência, finalmente liberta dos tabus e dos entraves que o Iluminismo conseguira romper no século XVIII, preparava aquilo que iria tomar no século $\mathrm{XX}$ a dimensão que estamos vendo e vivendo com surpreendente velocidade. (Moretto, 2003 p.9) 
No entanto, ao seguir os vestígios e pistas da produção visual em Victor Hugo encontramos um processo inspirador para as tendências vanguardistas muito além do seu tempo.

\section{A poética multiforme}

É notável o polimorfismo em Victor Hugo, poeta, dramaturgo, romancista, artista plástico, político e defensor de causas sociais são algumas atividades do artista/escritor. É característica de sua obra a virtuosidade em todos os meios que usa para afirmar a liberdade da arte. Arte que para Victor Hugo é ilimitada, no interesse pela pena que emprega em todos os sentidos (para escrever ou desenhar), como uma viagem no interior da textura, em que as linhas não têm contornos, e os contornos não são definitivos.

Nesse sentido, entre produções imagéticas e literárias, as zonas de contato e interação entre elas proporcionam reflexões críticas que transcendem as instâncias legitimadas no sistema das artes e abrem novos espaços de investigação. Tendo como referência os estudos de Georges Didi-Huberman (2003), Michel Butor (2000) dentre outros, o estudo evidencia Victor Hugo como exemplo supremo do artista que escreve, e do escritor que desenha, pois não podemos dissociar o poeta do artista e vice-versa.

Victor Hugo foi praticamente desconhecido como artista plástico, seus quatro mil desenhos jamais foram expostos durante sua vida. É mais celebrado como autor de inúmeras obras literárias, dentre as quais Notre-Dame de Paris (1831), Os Miseráveis (1862), Os trabalhadores do Mar (1866), O homem que ri (1869). Entretanto, Baudelaire reconheceu a importância de sua obra visual, ao revelar a técnica de Victor Hugo como um processo de pesquisa não dogmático, surpreendente e original. Com efeito, trata-se de uma espécie de cozinha de meios líquidos.

Baudelaire o considerava como um "revelador de abismos" e via os mistérios em todas as partes, confirmava a equivalência entre pintura e poesia, não separando as atividades do artista/escritor. Apenas dizia que a mensagem do escritor é mais complexa que a do pintor. Para Baudelaire o pintor se reserva retratar o lado escuro e monstruoso das coisas, e o poeta experimenta sensações de espanto e as traduz em turbulências 
conflitivas em acumulações e desmoronamentos de versos. Salienta que enquanto o escritor entra na ação diante dos elementos, o pintor fica hipnotizado com o espetáculo inquietante. A diferença entre o pintor e escritor para Baudelaire é que o pintor seria autodidata enquanto o escritor profissional.

Naquele contexto, não era muito comum os artistas se dedicarem igualmente às duas artes, pintura e literatura, com a mesma intensidade. Temos o caso de William Blake (Londres 1757-1827), poeta e pintor, gravador ilustra os seus próprios livros. Blake redimensiona o livro com o seu desejo de unidade e verdadeira osmose entre as palavras e as imagens. $\mathrm{O}$ artista grava os textos e as imagens sobre uma única placa de cobre e depois de impressa ele ainda desenha com aquarela, particularizando cada exemplar que ele produz. Blake busca traduzir em imagens a grande força visionária da sua inspiração poética e linguística, contribuindo para a renovação e sensibilidade típica do romantismo.

A liberdade de criação e imaginação é marca do visionário Victor Hugo, que afirma a liberdade na arte. A visão é uma construção mental, uma confluência de significações. Em suas obras visuais apesar da pequena dimensão dos desenhos e pinturas, utiliza uma espécie de "mistura bizarra", Victor Hugo desenha os objetos que encontra em seu entorno, e como um sonho usa proporções colossais ao representa-los. (Figura 1) Ao reabilitar os objetos do cotidiano, em suas dimensões micro ou macrocósmicas ele opera uma espécie de revolução ou inovação comparada, um século mais tarde, a de Andy Warhol quando utiliza elementos do cotidiano e afirma que "tudo é Belo" ou René Magritte e suas criações entre consciência e sonho, entre razão e irracional. 


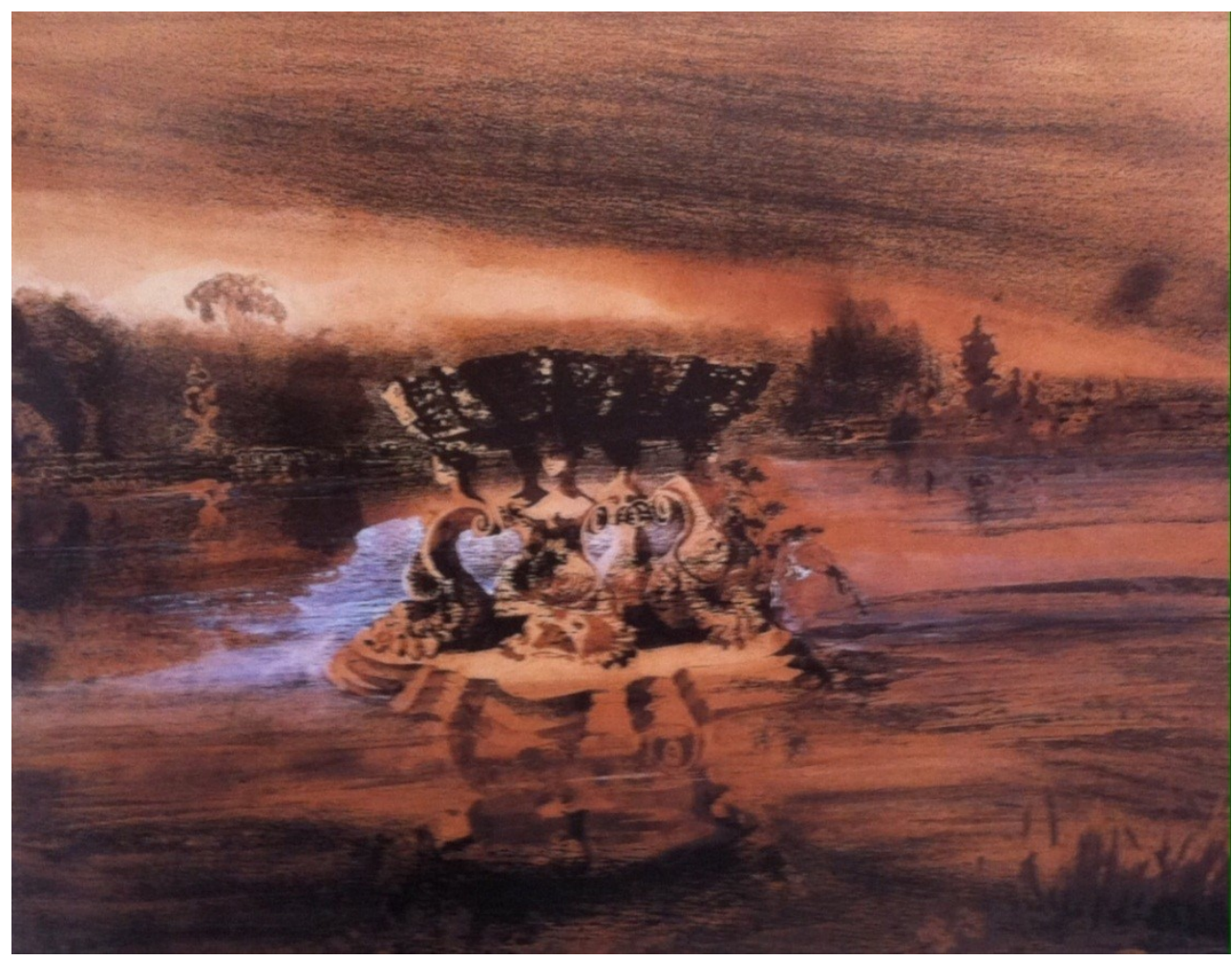

Figura 1. Victor Hugo, Saleiro - Fonte, aguada de tinta sépia, frotagem e guache sobre papel, $405 \times 600 \mathrm{~mm}, 1850$

As constantes viagens desde sua infância muito contribuíram para o imaginário do poeta em suas obras literárias e gráficas (especialmente as realizadas entre os anos 1834 a 1843). Nápoles, Madrid, Bretanha, Picardia, norte da França, Normandia, Bélgica, Suiça, Alemanha, bordas do Reno são alguns dos lugares visitados por ele. Victor Hugo encontra inspiração imagética em suas viagens, lugares diversos, marinhas, céus e paisagens povoadas de cidades e fortalezas em ruina. (Figura 2) 


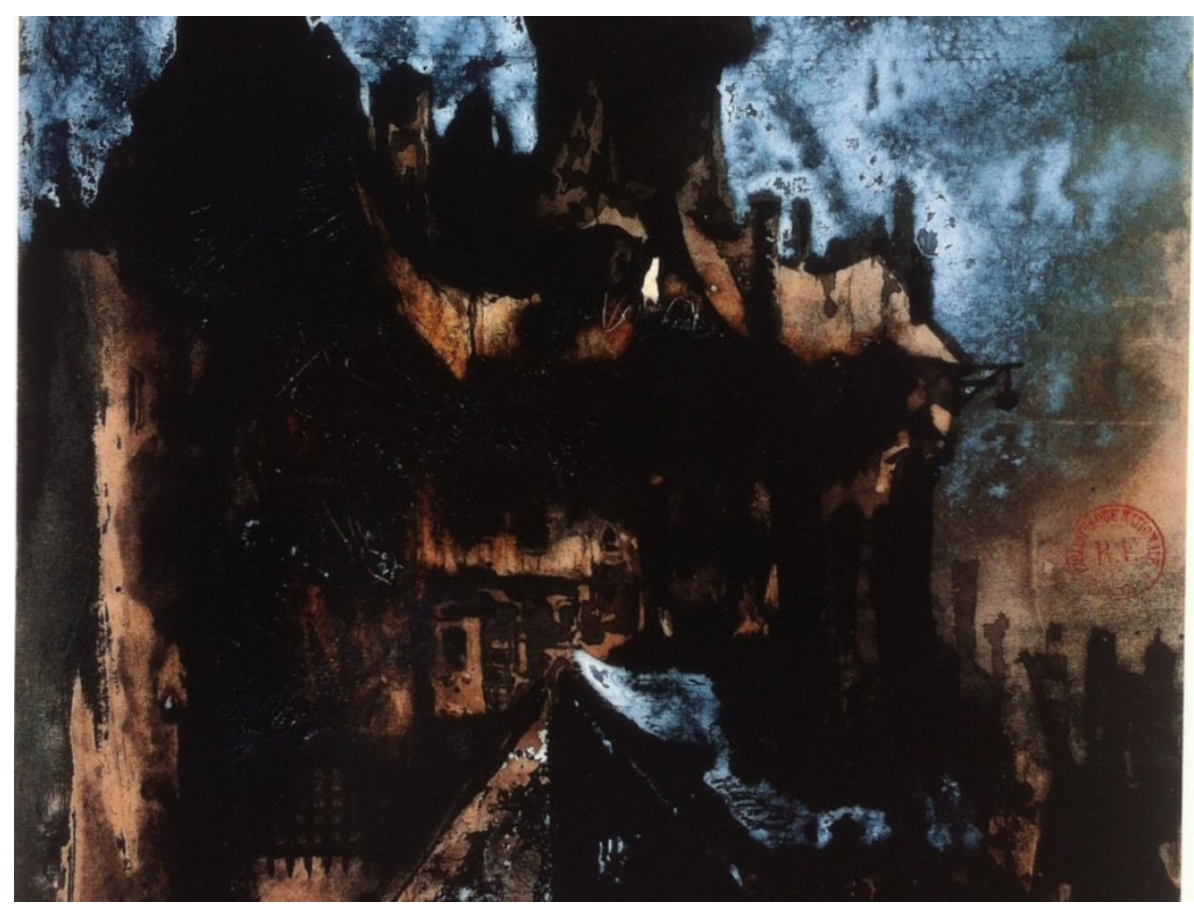

Figura 2. Victor Hugo, Fortaleza rodeada de casas, pena e tinta sépia e aguada sobre papel, 273 x 253 mm, 1856. Bibliothèque Nationale de France, NAF 24807, f.44

Em anos posteriores (entre 1861 e 1871), as viagens constantes para Bélgica, Suiça e Luxemburgo são associadas às visitas a museus, castelos, catedrais, em que Victor Hugo coleta objetos e documentos que impregna no seu imaginário antecipando o uso do objeto encontrado (l'objet trouvé) surrealista. (Figura 3)

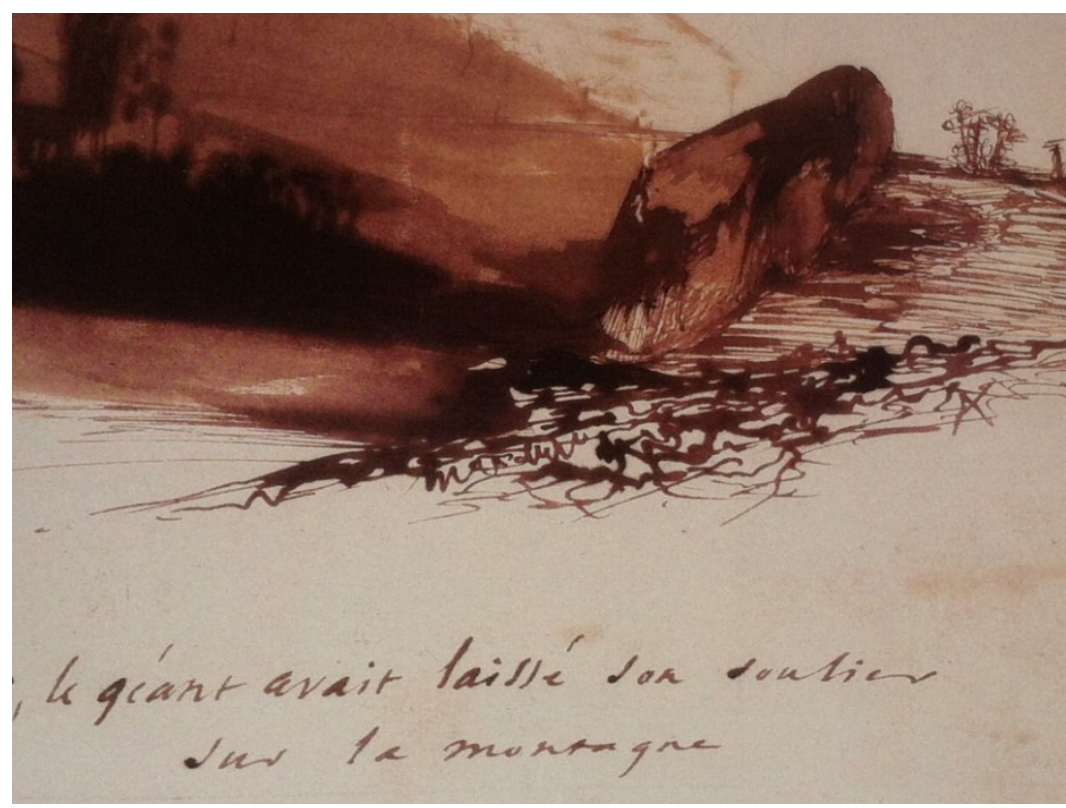

Figura 3. Victor Hugo, Ou o gigante havia deixado o sapato na montanha, pena e tinta sépia e aguada sobre papel, 147 x 225 mm, 1864. Maison de Victor Hugo, Inv. 62 
O cenário iconográfico de Victor Hugo está repleto de paisagens e marinhas impregnadas em manchas, traços, aguada, monotipia, texturas as mais inusitadas que lembram técnica da frotagem usada pelos surrealistas, especialmente Max Ernest. Navios e embarcações em tempestades e tormentas, numa atmosfera de desamparo são envolvidos por imensas ondas que celebram a imensidão e grandiosidade do sublime, do inquieto, do acaso e do mar, tema recorrente em sua obra. (Figura 4) Hugo incorpora uma "potência de metamorfose" nas imagens que fluem. "Ao ler Ovídio e compreende que a noção de metamorfose podia dar a regra poética e filosófica de todas as multiformidades, de todas as analogias." (DIDI-HUBERMAN, 2003)

Se para Victor Hugo toda a natureza é uma permuta, em sua poética os fenômenos se entrecruzam. E o mar, em seus grandes movimentos de fluxo e de refluxo, de extensão e de profundidade aparece como um eixo condutor inesgotável em sua obra. Tudo retorna poeticamente para o mar. Por que o tempo e o ser são um oceano vivo, um acúmulo de obras flutuantes.

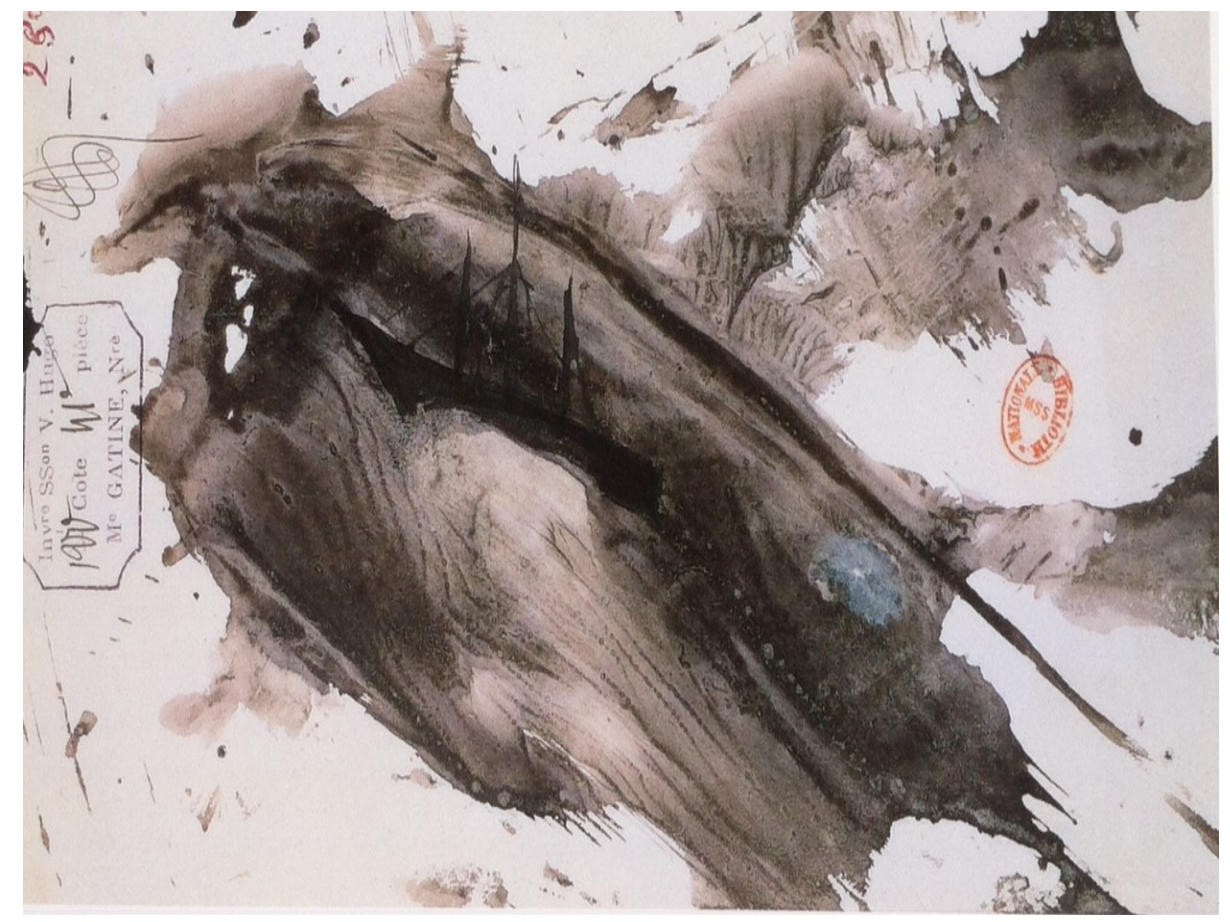

Figura 4. Victor Hugo, tinta negra e aguada sobre papel, 103 x $181 \mathrm{~mm}, 1875$. Bibliothèque Nationale de France, NAF 24810, f.230

Nas obras visuais de Victor Hugo, figura e fundo costumam se interpenetrar. Em seus desenhos, ele retoma (o material é quase o mesmo que usa para escrever) a pena de 
outro modo, ao invés de descrever, produz visualmente um naufrágio, por exemplo. Em Victor Hugo, encontramos essa dinâmica do meio fluído, como as ondas e todos os elementos marinhos.

Diante de tanto espaço poético, originalidade, liberdade, situamos Victor Hugo como pioneiro e até mesmo precursor da modernidade, ao antecipar uma arte que estava por nascer.

\section{Abismos e inovações}

Uma característica na poética multiforme hugoliana é possuir o "caos no pincel", termo usado por ele mesmo. Suas obras são inovadoras, experimentais e audazes. A frequente diversificação de meios marca a "poética filosófica" do artista que apresenta uma dinâmica própria, fluida. A arte poética de Victor Hugo é multiforme, no ritmo de seus textos, desenhos ou pinturas, mas de acordo com Didi-Huberman (2003) a originalidade dos seus processos gráficos aponta para uma "estética da imanência, que se deseja gesto e não representação, Darstellung e não Vorstellung, processo e não aspecto, contato e não distância".

Para Charles Renouvier (2002), "a imanência é, na linguagem de Victor Hugo, uma força obscura, irresistível, inerente em qualquer tempo aos seres, dominando-os". Trata-se do grande jogo do "mistério da vida" de que falava Baudelaire:

"Em tudo ele põe a palpitação da vida", escreve Baudelaire: compreendamos, em primeiro lugar, que Hugo toma tudo, toma "o tudo" - em sua infinita variedade - como campo de seu trabalho poético; mas que, em tudo, através de tudo, bate esta palpitação característica que é preciso chamar de $a$ vida. A arte poética de Hugo, o ritmo de seus versos, o tema de seus romances, a estrutura de seu pensamento, a energia de seus desenhos, tudo isso faz apelo a - ou tem sua origem em - uma filosofia da vida. (DIDI-HUBERMAN, 2003)

A aproximação dos seus procedimentos gráficos com a vida e o cotidiano, relembra uma espécie de cozinha em que Hugo experimenta materiais diversos, as barbas de pena, os resíduos de café, as esfregas, mergulhando inteiramente os desenhos em meios líquidos, o que suscita uma analogia entre o tema e a técnica, como a 
utilização da a mancha por exemplo. (Figura 5) $\mathrm{O}$ uso das manchas era comum como um método auxiliar para os desenhistas de paisagem no século XVIII, mas Hugo explora a mancha com maestria e a transforma em arte. (Figura 6)

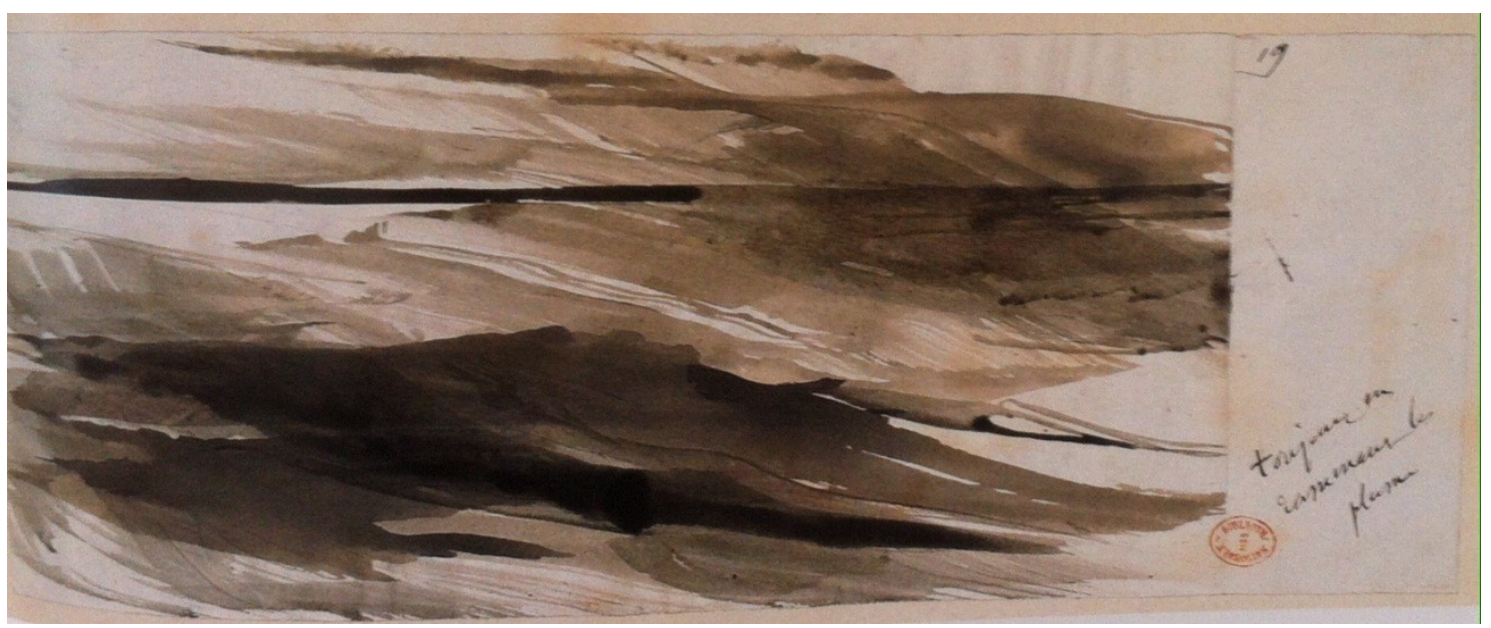

Figura 5. Victor Hugo, Sempre trazendo a pena, tinta sépia e aguada sobre papel, 105 x 280 mm, Bibliothèque Nationale de France, NAF 13351, f.19.

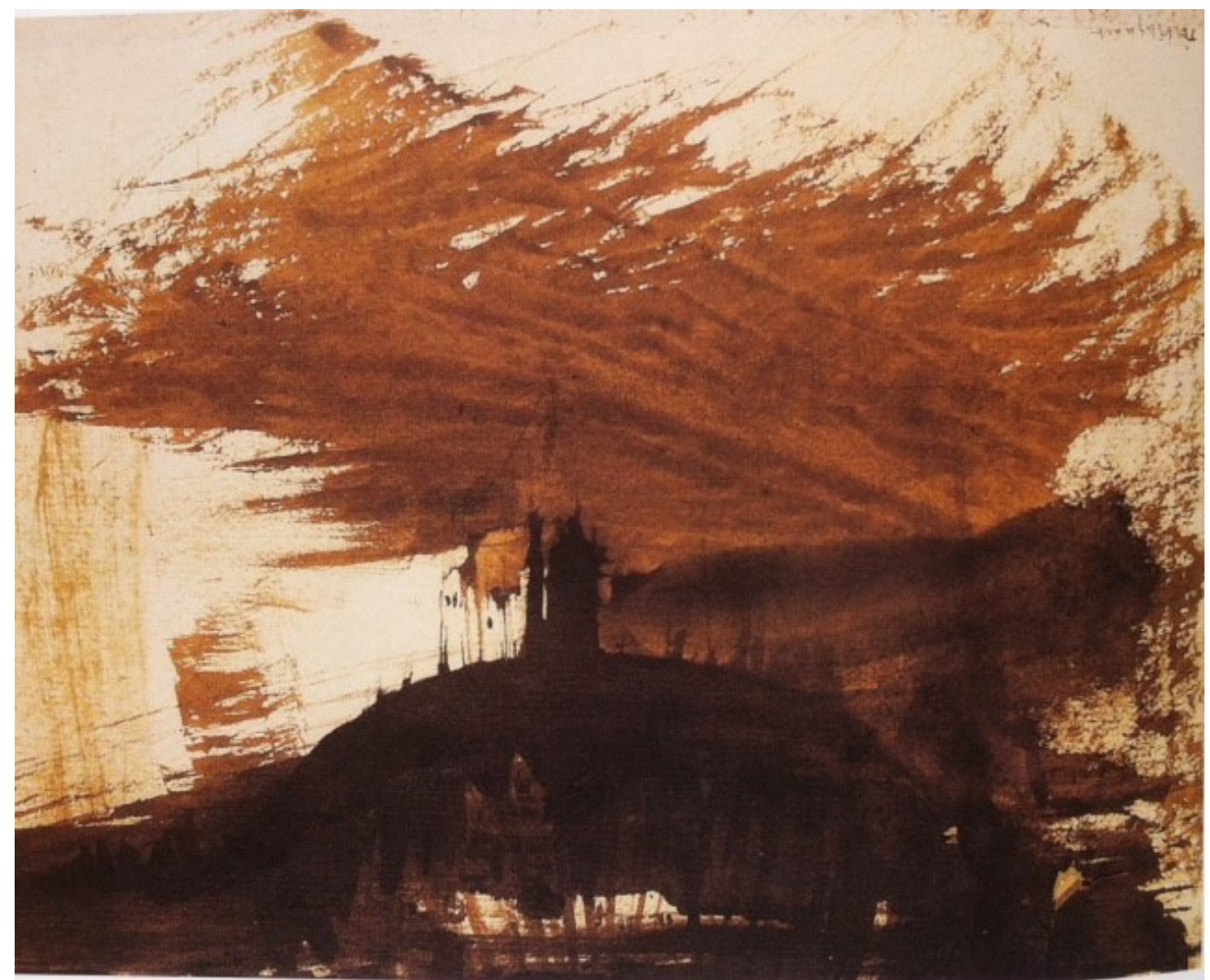

Figura 6. Victor Hugo, O Porto, pena, tinta sépia aguada sobre papel, 143 x 184 mm, 1856-1857, Petit Palais 


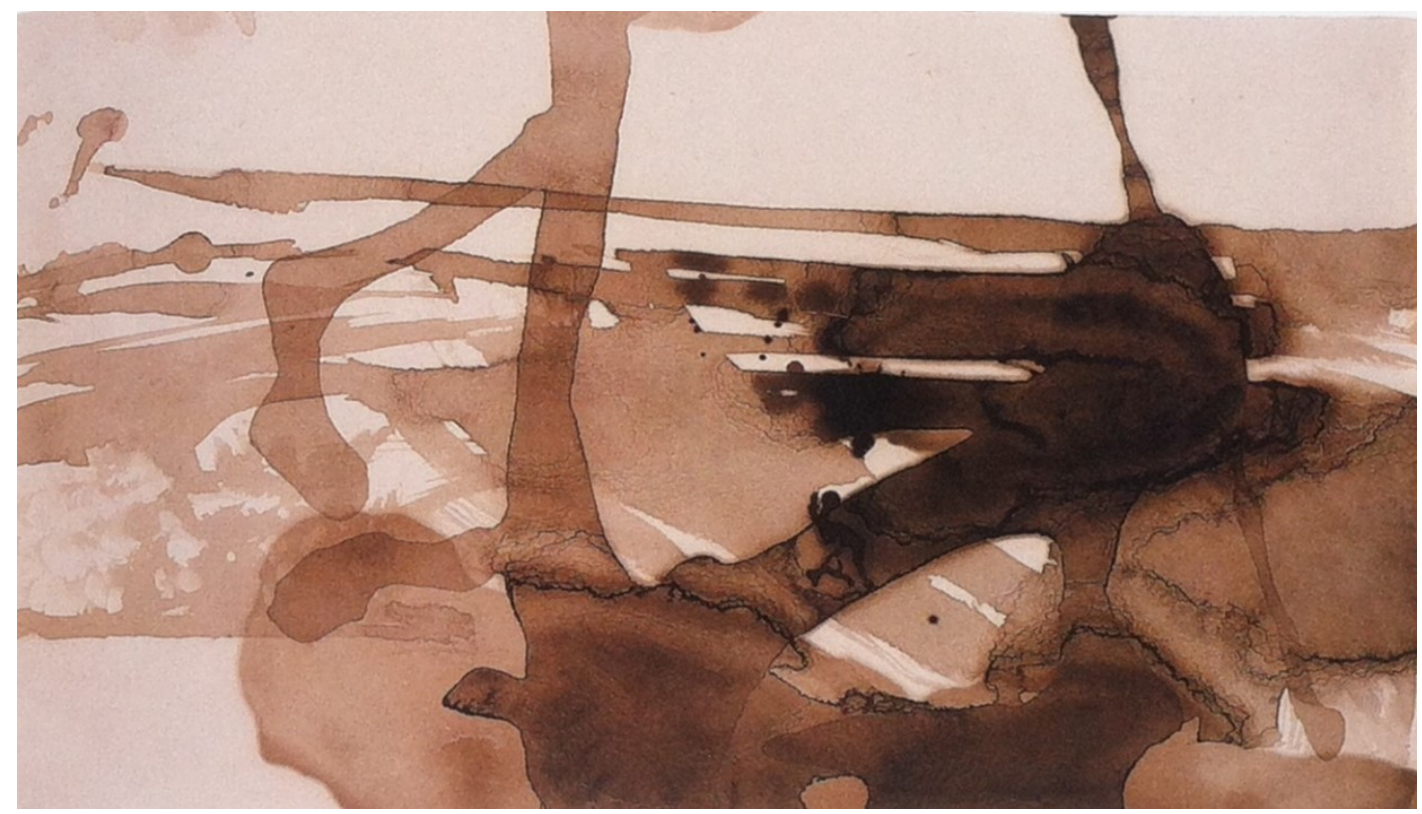

Figura 7. Victor Hugo, Manchas, tinta sépia e aguada sobre papel, 133 x $243 \mathrm{~mm}$. Maison de Victor Hugo, Inv.2428.

A iconografia hugoliana apresenta algumas características significativas, tais como, a dissolução: em vários níveis, manchas (líquidos) experimentos que se transformam em muitos elementos; a polissemia; a exploração de um mundo abismal, com grandes extensões esboçadas com pinceis grossos e a deformação e imaginação que fluem em seus pinceis (muito perceptíveis nas caricaturas).

Se com sua imaginação, seu abundante vocabulário, seu profundo sentido do mistério, Hugo abriu caminho para a poesia moderna, os procedimentos ousados e revolucionários para seu tempo prenunciam as vanguardas artísticas. (Figura 7) As transformações técnicas como o uso da colagem, muito recorrente no cubismo; a gratagem e frotagem e impressões usadas no surrealismo; as manchas de tinta ou vinho exploradas no informalismo (tachismo e dripping) e a espontaneidade que prescinde qualquer instrumento como o uso do dedo como pincel. Ao colecionar objetos e ressignificá-los ao justapô-los ele explora a multimaterialidade. (Figura 8) Em Hugo, a liberdade da obra gráfica é assinalada em suas palavras "meus desenhos são um tanto selvagens", e apesar das suas origens românticas, antecipa os procedimentos vanguardistas e conquistas fundamentais do século XX. 


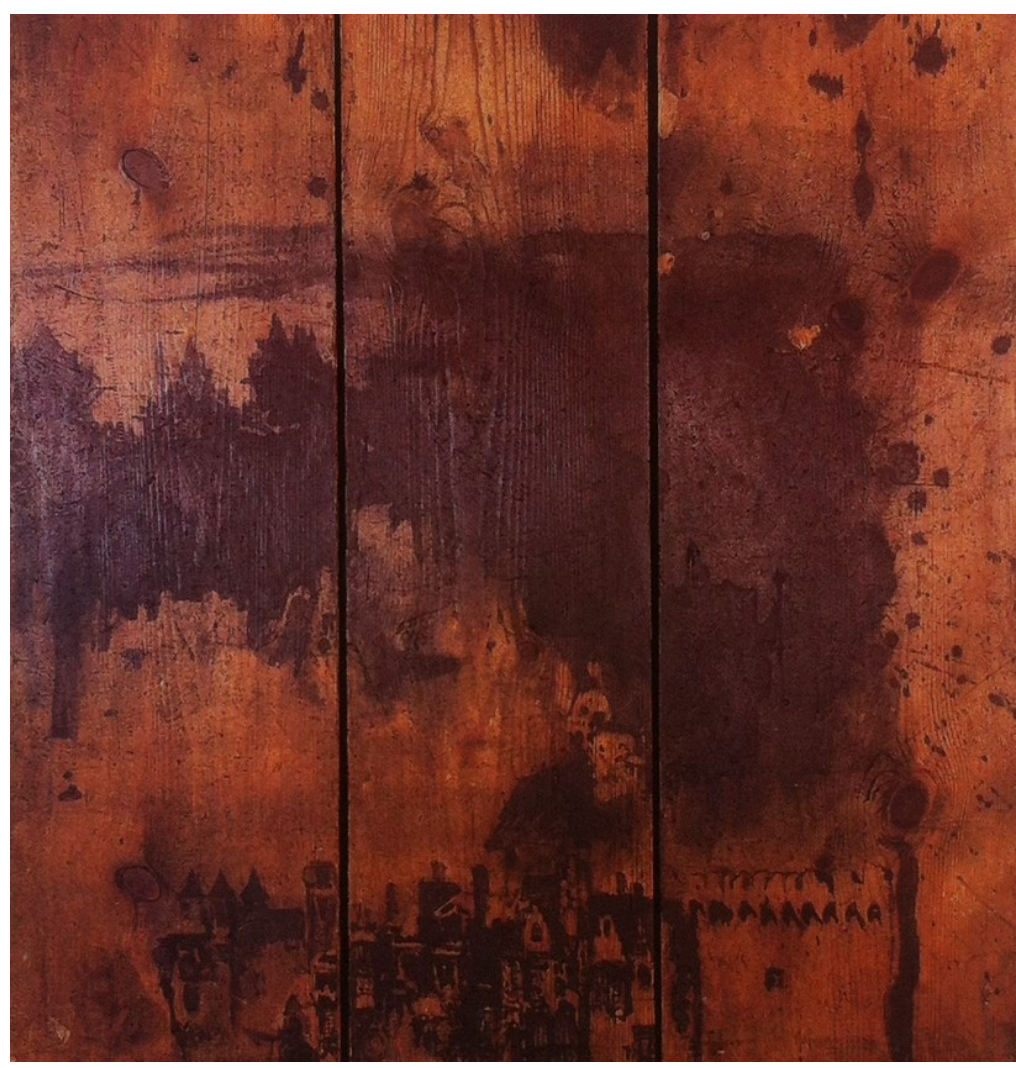

Figura 8. Victor Hugo, Painel pintado, tinta sépia e aguada sobre madeira, 654 x 600 mm, Maison de Victor Hugo, Inv.2040.

\section{CONSIDERAÇÕES FINAIS}

No século $\mathrm{XX}$, as fronteiras entre os gêneros, bem como entre os campos artísticos, se dissipam. Entretanto, salvo exceções, no interior da pluralidade, as preponderâncias se afirmam e se mantêm. Ainda são raros os exemplos de artistas que se dedicam igualmente às duas artes, pintura e literatura, com a mesma intensidade. $\mathrm{Na}$ imensa produção de Victor Hugo podemos vislumbrar a multiplicação de diferentes meios, vestígios da "poética filosófica" do artista que apresenta uma dinâmica própria, fluida e multiforme, no ritmo de sua escrita, desenho ou pintura e filosofia. Em Victor Hugo, encontramos essa dinâmica do meio fluído, como as ondas e todos os elementos marinhos, em que não há limites, mas um universo de signos que se tocam uns nos outros - um meio climático poético, em que o material não tem estabilidade porque é inesgotável e imenso. 


\section{REFERÊNCIAS}

BUTOR, Michel. La esperanza de la tinta. In Victor Hugo: dibujos. Fundación Colección Thyssen-Bornemisza. Madrid, 2000.

DIDI-HUBERMAN, Georges. A imanência estética. Alea vol.5 n.1 Rio de Janeiro Jan./July 2003

MORETTO, Fulvia M.L. Victor Hugo e o Romantismo, Lettres Françaises n.5, Araraquara: Unesp, 2003.

PRÉVOST, Marie-Laure. Victor Hugo: l'homme océan. Paris: Blibliothéque Nationale de France/ Seuil, 2002.

VICTOR HUGO “caos em el pincel” Dibujos. Fundación Colección ThyssenBornemisza. Madrid, 2000.

RAYMOND, M. De Baudelaire ao Surrealismo. Tradução de Fulvia Moretto e Guacira M. Machado Leite. São Paulo: Ed. USP, 1997.

RENOUVIER, Charles. Victor Hugo le philosophe (1900). Paris: Maisonneuve \& Larose, 2002. 